\title{
INVESTIGATING THE DEVIATION ANGLE METHOD FOR ENSURING DEFLECTION AT ONE-LANE RURAL ROUNDABOUTS
}

\author{
Nicola BERLOCO ${ }^{*}$, Pasquale COLONNA, Paolo INTINI, Vittorio RANIERI \\ Dept of Civil, Environmental, Building Engineering and Chemistry, Technical University of Bari, Bari, Italy
}

Received 02 August 2017; accepted 16 January 2018

\begin{abstract}
Roundabouts developed as a road intersection design option has resulted in a series of nonuniform design guidance criteria in Europe, as well as in the United States and other Countries. In addition to different design specifications about the geometry of the elements constituting a roundabout (width and lanes of the circulatory roadway, entry and exit legs, splitter island), the methods for guaranteeing that vehicle paths deflect through the roundabout are also different. These methods ensure proper travel speeds between conflicting traffic flows. Currently, the main parameters used by standards to control the deflection are the deflection radius, the entry path radius, and the deviation angle.

After a comparison between International deflection methods for roundabouts, this study checks the geometric requirements of the deviation angle for more than 7.000 hypothetical one-lane rural roundabouts. The Computer-Aided Design (CAD) drawing of the roundabouts takes into account the range of variability of their main geometric parameters, according to the Italian Standard. Subsequently, a number of the considered roundabouts checked with both the entry path radius and the German methods. Some results showing the greater effectiveness of the less popular deviation angle method are discussed. The main aims of this paper are:

1) to promote the deviation angle method, which is only used in Switzerland and Italy;

2) to improve standards, as regards the applicability and validity of the deflection angle method;

3) to help practitioners to know in advance the outcome of the deflection checks at the beginning of the iterative design process, once the boundary conditions are known.
\end{abstract}

Keywords: deviation angle, entry path radius, one-lane roundabout, roundabout deflection, rural roundabout, speed control.

\section{Introduction}

The modern roundabout is a circular intersection, successfully implemented worldwide over the past few decades. However, roundabout design guidance criteria are nonuniform. Some studies have extensively reviewed several International design practices, guidelines, and regulations, potentially leading to improved local standards able to meet the needs of modern roads.

An international review of roundabout design standards and guidelines was undertaken by Kennedy (2007) to support the revision of the United Kingdom (UK) Standard for Roundabouts. A design hierarchy for roundabouts was proposed depending on road types, speed limits on the approach roads (greater or lower than $65 \mathrm{~km} / \mathrm{h}$ ) and on the vehicular and non-motorised user flows. A "compact" roundabout was also proposed for low-volume roads, with one lane entries, exits, and circulatory carriageway.
The review of the International standards and guidelines carried out by (Montella, Turner, Chiaradonna, \& Aldridge, 2013) showed that the combined effect produced by different roundabout geometric elements on safety performance is more important than each single impact. Furthermore, several inconsistencies in the Italian standard have been identified (the absence of splitter island design, the number of exit lanes limited to 1 , the unfeasible planning of roundabouts on divided highways); and recommendations for improvement have been proposed. The authors suggested the performance-based geometric design as the best approach, by better calibrating safety performance functions by means of additional geometric design parameters.

Pilko (2017) and Bezina, Stančerić, and Ahac (2017) conducted an International literature review on roundabout geometric design and traffic efficiency practices,

${ }^{*}$ Corresponding author. E-mail: nicola.berloco@poliba.it 
mainly focused on capacity and delay, to introduce and improve the Croatian guidelines. The indication of the best models and simulation software to be used for analysing and improving operational features of roundabouts was the most important goal of this comprehensive and systematic field-analytical study on existing roundabouts.

Almost all International roundabout design guidelines include specific requirements on how to control speeds, while approaching and negotiating the roundabout, considering the vehicle path deflection. In detail, the main parameters used to control speeds at roundabouts by ensuring the vehicle path deflection are the deflection radius, the entry path radius and the deviation angle, defined below and better explained in Figure 1:

- The deflection radius is the radius of the vehicle path through the circulating roadway. The largest value of the radius is set to control the operational speeds on the roundabout. This method was formally proposed in UK and Australian Guidelines (Arndt, 2008), and later replaced by other methods, but is used in France.

- The entry path radius is the path radius of a vehicle, which is approaching the roundabout by entering the circulating roadway. It defined as the "minimum radius on the fastest through path before the yield line" (NCHRP, 2010). It is possible to limit the speed of drivers who are entering in the roundabout, by limiting the entry path radius (Colonna, Berloco, Intini, Perruccio, \& Ranieri, 2016). This approach is used in several countries (Afezolli \& Paçi, 2012).

- The deviation angle is the angle included between the two tangent lines to the $3.5 \mathrm{~m}$ offsets of the entry and exit kerb radii as in Figure 1. Setting a minimum value for this angle may lead to controlling the speeds of drivers who have to negotiate the roundabout, by ensuring an appropriate curved path. This approach is used in Italy and Switzerland.

Some other roundabout design standards use different geometric parameters to control the deflection of trajectories from the ones listed above. For example, according to German standards, a satisfactory deflection is considered to be achieved when the radius of the central island is at least twice the entry lane width (Figure 1a).

The following Table 1 summarizes the parameters controlling the deflection of trajectories provided in different roundabout design standards reviewed (from the United States of America (USA), Australia, and some European countries), better explained in Figure 1.

While the aims of the above listed methods are similar, the specific design requirements for achieving them are different. Clearly, independently of the specific need, deflection prescriptions limit the geometric roundabout configurations, usually chosen by the designers. For this reason, technical studies may help practitioners in addressing the geometric design aspects of roundabouts with particular regard to the deflection requirements, which in some cases are hard to fulfil. Moreover, the main three deflection requirements are normally affected by the other geometric elements of the roundabout, and the design process is usually iterative. Hence, providing practitioners with methods to know in advance the relationships between different geometric roundabout parameters and the deflection requirements could be very helpful.

However, the literature specifically related to the topic of roundabout deflection is scarce. There are some stud-

Table 1. Deflection parameters for rural one-lane roundabouts in several countries

\begin{tabular}{|c|c|c|c|c|c|c|c|c|c|c|}
\hline \multirow[b]{3}{*}{$\begin{array}{l}\text { Deflection } \\
\text { parameters }\end{array}$} & \multicolumn{10}{|c|}{ Country and Standard/Regulation } \\
\hline & France & $\begin{array}{l}\text { The } \\
\text { Netherlands }\end{array}$ & Sweden & Spain & UK & USA & Australia & Switzerland & Italy & Germany \\
\hline & 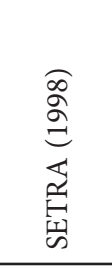 & $\begin{array}{l}a \\
2 \\
2 \\
ٍ \\
3 \\
0 \\
0 \\
0\end{array}$ & 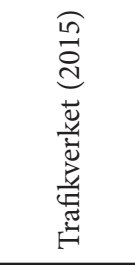 & 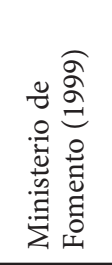 & 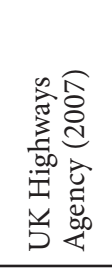 & 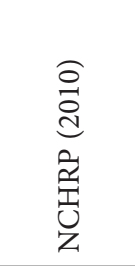 & 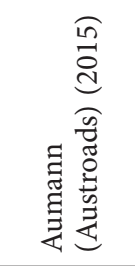 & 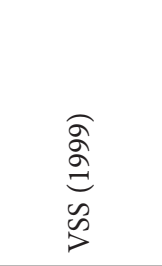 & 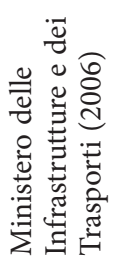 & 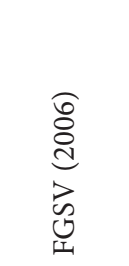 \\
\hline $\begin{array}{l}\text { Radius of } \\
\text { deflection }\end{array}$ & $\leq 100 \mathrm{~m}$ & $\leq 23 \mathrm{~m}$ & $\begin{array}{l}\leq 90 \mathrm{~m} \text { or } \\
\leq 30 \mathrm{~m}^{*}\end{array}$ & & & & & & & \\
\hline $\begin{array}{l}\text { Entry path } \\
\text { radius }\end{array}$ & & & $\begin{array}{l}\leq 90 \mathrm{~m} \text { or } \\
\leq 30 \mathrm{~m}^{*}\end{array}$ & $\leq 100 \mathrm{~m}$ & $\leq 100 \mathrm{~m}$ & $\begin{array}{l}\leq 52 \mathrm{~m} \text { or } \\
\leq 66 \mathrm{~m}^{\star *}\end{array}$ & $\begin{array}{l}\leq 55^{\star * *} \mathrm{~m} \\
\text { desirable }\end{array}$ & & & \\
\hline $\begin{array}{l}\text { Deviation } \\
\text { angle }\end{array}$ & & & & & & & & $\begin{array}{l}\geq 45^{\circ} \text { in } \\
\text { case of } \\
\alpha<70^{\circ}\end{array}$ & $\geq 45^{\circ}$ & \\
\hline $\begin{array}{l}\text { Lateral } \\
\text { displacement }\end{array}$ & & & & & & & & & & $\geq 2 L_{c}$ \\
\hline
\end{tabular}

Notes: ${ }^{\star} \leq 90 \mathrm{~m}$ for design speed $\leq 60 \mathrm{~km} / \mathrm{h}, \leq 30 \mathrm{~m}$ for design speed $\leq 30 \mathrm{~km} / \mathrm{h} ;{ }^{\star \star} \leq 52 \mathrm{~m}$ for super elevation equal to $+0.02 ; \leq 66 \mathrm{~m}$ for super elevation equal to $-0.02{ }^{* * *}$ this value is increased ( $\leq 100 \mathrm{~m}$ for speed $\leq 40 \mathrm{~km} / \mathrm{h}$ ) when the desired speed on the leg placed before the roundabout is $<90 \mathrm{~km} / \mathrm{h}$. 
ies on the design aspects of roundabouts, which consider the entry path radius method in detail (see e.g. ARNDT, 2008; Easa \& Mehmood, 2004; Flannery, 2001; Mehmood \& Easa, 2006). The study by Easa and Mehmood (2004) specifically provides an optimized method for designing the geometry of roundabouts, also considering the deflection requirements. However, the deviation angle method was mainly addressed by earlier studies from a safety perspective (Sacchi, Bassani \& Persaud, 2011; Sadeq \& Sayed, 2016; Spacek, 2004). In a recent Italian study on roundabout crashes (Montella, 2011), a very large entry path radius $(R>100 \mathrm{~m})$ was identified as a contributory factor in almost $30 \%$ of the crashes.

Ambros, Novák, Borsos, Hóz, Kieć, Machciník, and Ondrejka (2016) developed accident prediction models for roundabouts, based on accident, traffic and geometric data for 72 roundabouts in four Central-European countries. They found injury accident frequencies increasing with the traffic volume and apron width, and decreasing with the deflection parameters (in terms of both entry and deviation angles).

This study is intended as a research contribution to deepen the comparison between the deflection methods for roundabout design, and it is specifically focused on the deviation angle method. Designing a roundabout is an iterative process. In most cases, checking the roundabout deflection is the last step in the design process. Thereafter, the consistency between the speeds related to the entry, circulatory and exit (rarely) trajectories are verified. In several cases, the deflection check gives a negative output and the designer has to repeat the design process, by modifying some geometric input parameters. This is the case of converting existing intersections into roundabouts, given some constraining boundary conditions (e.g. limited diameter or roads at intersections with angles different than $90^{\circ}$ ).

Starting from this evidence, the aims of the study are:

- to review some key international practices for ensuring path deflections at roundabouts;

- to find the minimum geometric standards for a generic roundabout, which are able to satisfy the deviation angle check (taking into consideration the Italian legislation);

- to compare results obtained from the simulation performed considering the deviation angle method (using the Italian reference standard) with the entry path radius method (using the US reference standard) and the German method;

- to provide some possible improvements in standards using the deviation angle method (in particular the Italian one, used as a reference).

To reach this aim, the deflection angles of more than 7.000 hypothetical roundabouts plotted in a CAD environment were measured. A number of the considered roundabouts were checked with both the entry path radius and the German methods. The high number of roundabouts examined derives from the high number of geometrical parameters considered in the graphic simulation. A simulation of the variability of these parameters was conducted, systematically, within the validity intervals indicated in the Italian roundabout geometric standard taken as a reference (Ministero delle Infrastrutture e dei Trasporti, 2006).

The remainder of the paper is structured as follows. Section 1 is devoted to present some International standards on the deflection requirements. An overview of the Italian standard used as a reference for the design of roundabouts is presented in Section 2, while the methods employed for the research are detailed in Section 3. The following Section 4 presents the results obtained through the simulation of the geometry of the reconstructed roundabouts as well as the comparison between the deviation angle and the method of the entry path radius. The results are discussed in Section 5, in which some proposals are also advanced for improving the Italian Standard based on the results obtained. Conclusions about this study are then drawn, also giving some indications about possible future developments.

\section{International comparison of roundabout deflection methods}

In this section, the requirements provided by the main international standards to control the speed through the deflection are summarized. A generic depiction of the deflection measures adopted in seven European countries, the USA and Australia, is given in Figure 1. Most other countries adopt one of the methods described or a combination thereof.

\subsection{The deflection radius method}

\section{The French method}

According to The Design of Interurban Intersections on Major Roads. At-Grade Intersections (SETRA, 1998), the path deflection is the radius of the arc passing $1.5 \mathrm{~m}$ from the edge of the central island and $2 \mathrm{~m}$ from the edges of the entry and exit lanes (Figure 1c). Its radius should be less than $100 \mathrm{~m}$. The recommended value is $30 \mathrm{~m}$.

\subsection{The entry path radius method}

\section{The Spanish method}

The Recomendaciones sobre glorietas (Ministerio de Fomento, 1999) set the maximum entry path radius to $100 \mathrm{~m}$ in order to ensure a reasonable entry speed (Figure 1f). However, this value corresponds to an entry speed equal about to $50 \mathrm{~km} / \mathrm{h}$. For this reason, the Spanish standard is closer to the Anglo-Saxon standards than other standards from continental Europe.

\section{The UK method}

The TD 16/07 - Geometric design of roundabouts (UK Highways Agency, 2007) assumes a width of $2 \mathrm{~m}$ for the entry path. In this way, a distance of at least $1 \mathrm{~m}$ between the centerline of the following vehicle and any kerb or edge marking may be kept (Figure 1f). The path starts $50 \mathrm{~m}$ in advance of the give way line. The entry path radius is as- 
sumed the smallest radius of this path. It is measured over the smallest best-fit circular curve over a distance of $25 \mathrm{~m}$ on the entry path close to the give way line, but less than or equal to $50 \mathrm{~m}$ from it. The entry path radius must be lower than or equal to $70 \mathrm{~m}$ at urban compact roundabouts and $100 \mathrm{~m}$ at all other roundabouts.

\section{The US method}

Guidelines about roundabout design in the US are provided in Roundabouts: An Informational Guide - second Edition (NCHRP, 2010), replacing the first edition (NCHRP, 2000). Those guidelines use a method for plotting the entry path similar to the British method. They also recommend a maximum theoretical entry design speed.

In detail, the entry path radius is the smallest best-fit circular curve of at least $20 \mathrm{~m}$ to $25 \mathrm{~m}$ measured on the fastest path, advanced less than or equal to $50 \mathrm{~m}$ from the entrance line. The fastest path is obtained in turn by drawing the curve constrained by the offsets indicated in Figure 1f. Hence, in correspondence to the entry radius so determined, the speeds must be lower than the speeds reported in Table 2 . The safety check is aimed at the optimum goal of obtaining the smallest possible speed differential between the traffic flowing in the circulatory lane of the roundabout and the traffic entering from the entry lanes.

Eqs 1-2 provide the simplified relationship between speed and radius reported in (NCHRP, 2010), used to assign the speed to a given entry path radius, in case of positive or negative super elevation.

$$
\begin{aligned}
& V=3.4415 R^{0.3861} \text { for } e=+0.02, \\
& V=3.4614 R^{0.3673} \text { for } e=-0.02,
\end{aligned}
$$

where $V$ - speeds (mph); $R$ - radius (ft); $e$ - super elevation $(\mathrm{ft} / \mathrm{ft})$.

\subsection{The deviation angle method}

\section{The Swiss method}

The SN 640263 Carrefours giratoires (VSS, 1999) recommends observing a deviation angle $\beta \geq 45^{\circ}$ (Figure 1e). In general, the need for a deviation angle $\beta \geq 45^{\circ}$ is satisfied in the case of roundabouts with four legs having a large inscribed circle diameter (ICD) $(>32 \mathrm{~m})$. The Swiss standard also provides the correlation between the deflection angle $\beta$ and the entry angle $\alpha$ (between the vehicle entry path and

Table 2. Recommended maximum entry design speeds (Rodegerdts et al., 2010)

\begin{tabular}{|l|c|}
\hline Site category & $\begin{array}{c}\text { Recommended maximum theoretical entry } \\
\text { design speed }\end{array}$ \\
\hline $\begin{array}{l}\text { Mini- } \\
\text { Roundabout }\end{array}$ & $20 \mathrm{mph}(30 \mathrm{~km} / \mathrm{h})$ \\
\hline Single lane & $25 \mathrm{mph}(40 \mathrm{~km} / \mathrm{h})$ \\
\hline Multilane & $25 \mathrm{mph}$ to $30 \mathrm{mph}(40 \mathrm{~km} / \mathrm{h}$ to $50 \mathrm{~km} / \mathrm{h})$ \\
\hline
\end{tabular}

the tangent to the inscribed circle diameter): the recommendation of $\beta \geq 45^{\circ}$ is mandatory in the case of $\alpha<70^{\circ}$.

However, the same standard also accepts smaller $\beta$ angles to calculate the circulatory speeds used for visibility checks $\left(40 \mathrm{~km} / \mathrm{h}\right.$ for $\beta<20^{\circ}, 35 \mathrm{~km} / \mathrm{h}$ for $20^{\circ} \leq \beta \leq 45^{\circ}$, $30 \mathrm{~km} / \mathrm{h}$ for $\beta>45^{\circ}$ ). In fact, the Swiss standard is composed of recommendations and therefore allows more freedom to the designers.

\section{The Italian method}

The Italian deflection requirement in DM 2006 - Guidelines for the Design of Road Intersections (Ministry of Public Works and Transport, 2006) is based on the deviation angle $\beta$, the same as the Swiss one. The deviation angle is obtained through the following process:

a) draw the offset curve at $3.50 \mathrm{~m}$ of both the entry and exit kerb radii;

b) plot the lines at a tangent to both the offset curves drawn at the earlier stage, and the non-mountable kerbs of the central island;

c) measure the angle included between the two obtained tangent lines.

A deviation angle $\beta$ value greater than or equal to $45^{\circ}$ is recommended for each crossing leg. This requirement is valid for all types of roundabouts, independently of their diameters.

\subsection{Other methods}

\section{The Dutch method}

Concerning the speed reduction to be obtained at rural one-lane roundabouts, the Dutch guidelines (CROW, 1998) differ from the FHWA (U.S. Federal Highway Administration) guidelines (approach speed of $35 \mathrm{~km} / \mathrm{h}$ and $40 \mathrm{~km} / \mathrm{h}$, respectively). On single-lane roundabouts, all aspects of safety improve when the largest vehicle path curvature is used (Figure 1b). According to the Dutch regulations, the relationship between the speed $\mathrm{V}$ on the curved path and its radius $\mathrm{R}$ is represented by Eq. (3) and the speed through the roundabout is variable between $30 \mathrm{~km} / \mathrm{h}$ and $35 \mathrm{~km} / \mathrm{h}$. Hence, the deflection radius falls in the range between $16 \mathrm{~m}$ and $23 \mathrm{~m}$.

$$
V_{i}=7.4 \sqrt{R_{i}} .
$$

\section{The German method}

The German guidelines (FGSV, 2006) require the lateral displacement of the vehicle entering the roundabout to be at least twice the approach lane width $\left(L_{c}\right): R_{\text {int }} \geq 2 L_{c}$, as shown in Figure 1a.

\section{The Swedish method}

The Swedish guidelines (Trafikverket, 2015) require both the entry path radius and the deflection radius to be smaller than a given threshold (Figure 1d). This value is equal to $90 \mathrm{~m}$ for design speed $\leq 60 \mathrm{~km} / \mathrm{h}$ (rural roundabouts), and $30 \mathrm{~m}$ for design speed $\leq 30 \mathrm{~km} / \mathrm{h}$ (urban roundabouts). 
a)

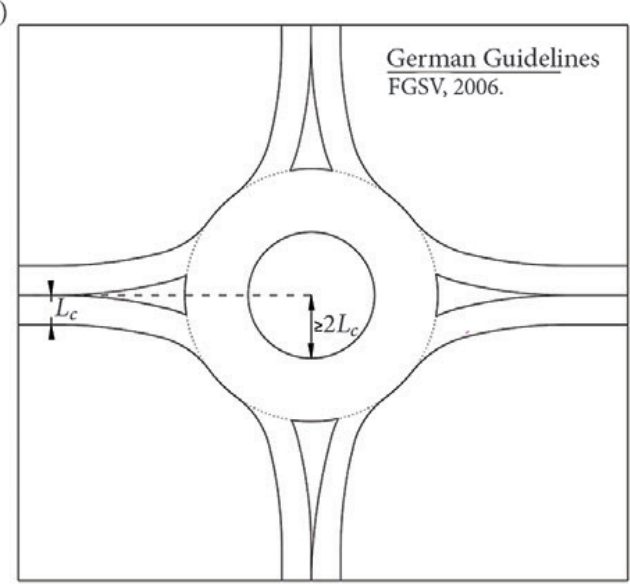

c)

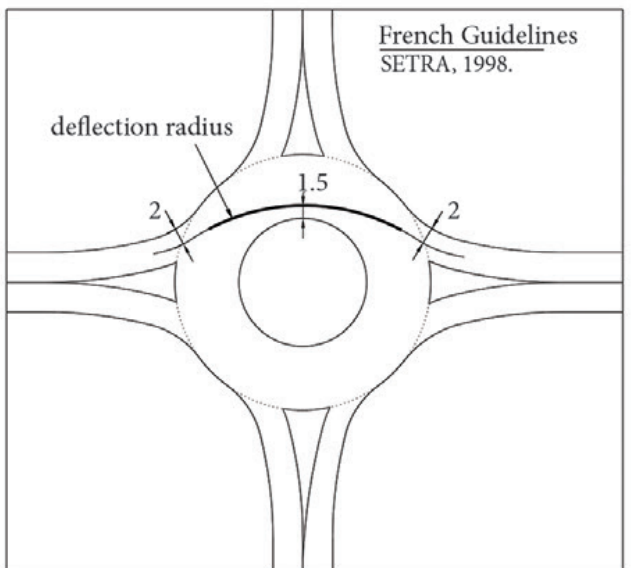

b)

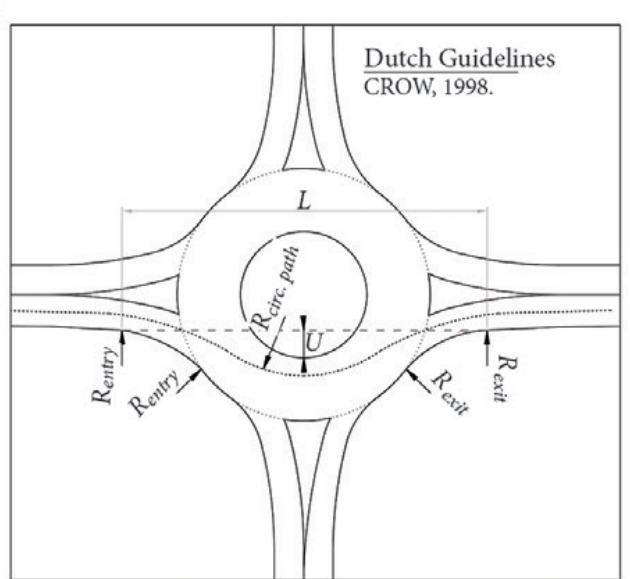

d)

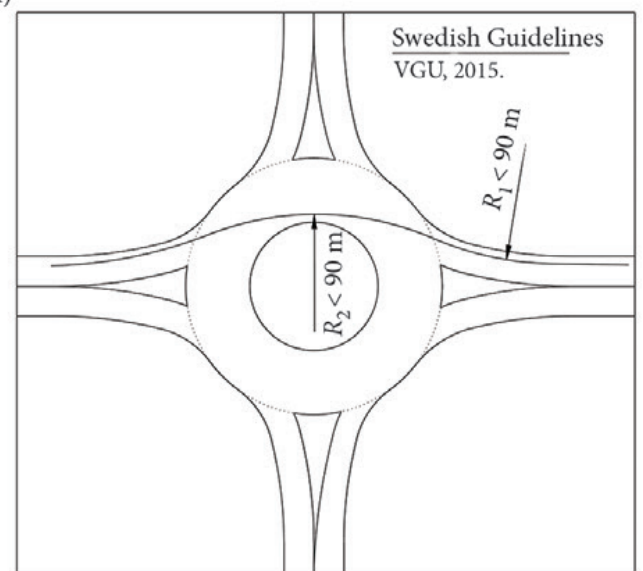

e)

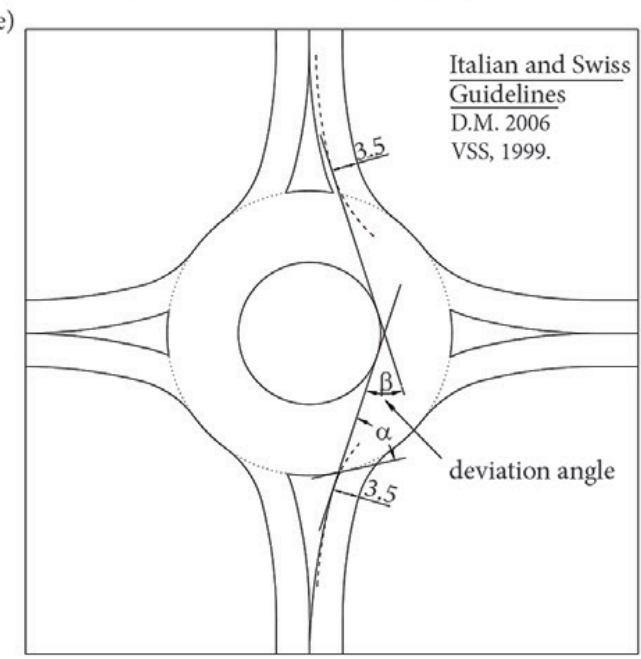

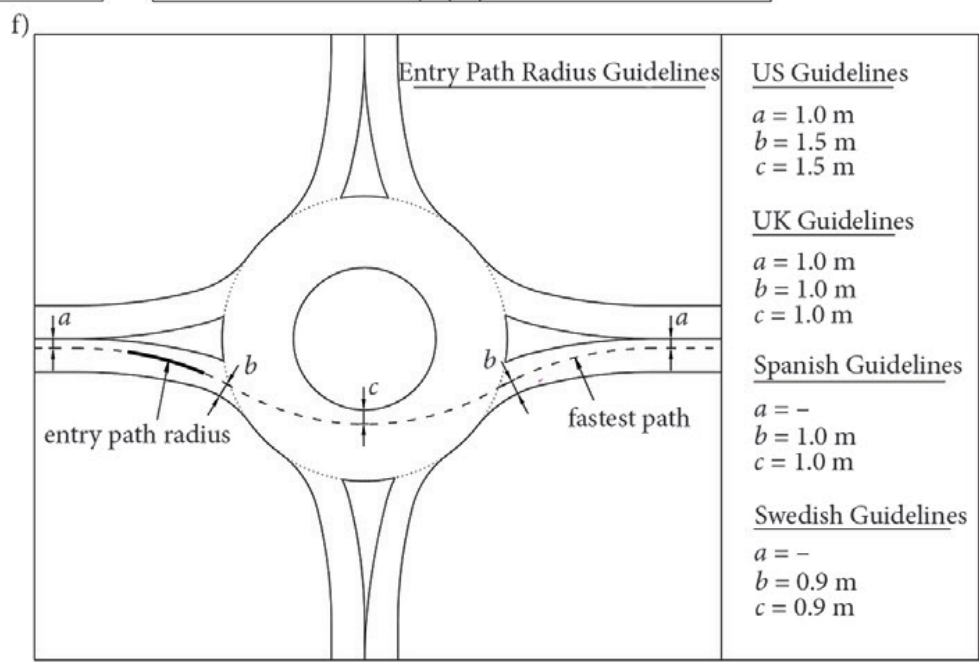

Figure 1. Summary of the main parameters used for controlling deflection at roundabouts

\section{Overview of the Italian roundabout design standards}

Since the Italian standard has been used as a reference in the simulations carried out, it is briefly introduced as follows. Among the geometric standards considered as a reference for conducting the analysis, the Italian standards were preferred to the Swiss ones, because they need further developments.

The Italian DM 2006 "Functional and geometric Standard for building road intersections" also includes "Round- about Intersections", very concise specific information about the circular intersections. The Italian nomenclature is different from any of the foreign ones considered in this study as regards roundabout dimensions, except for mini roundabouts with some slight differences (Tollazzi, 2015).

The Standard considers three basic categories of roundabouts, according to the ICD, valid both in rural and in urban contexts:

- large (conventional) roundabouts (with $40 \leq \mathrm{ICD} \leq$ $50 \mathrm{~m}$ ); 
- compact roundabouts (with $25 \leq \mathrm{ICD}<40 \mathrm{~m}$ );

- mini roundabouts (with $14 \leq \mathrm{ICD}<25$ ).

In this article, the word "conventional roundabout" translated from the Italian standard was converted into "large roundabouts" to prevent misunderstandings about the International meaning of "conventional roundabouts". A further distinguishing element, among the types of roundabouts, is the central island design, which may be partly mountable (truck apron) in the case of mini roundabouts with ICD included between 25 and $18 \mathrm{~m}$, while it becomes fully mountable for those with ICD included between 18 and $14 \mathrm{~m}$. The compact and large roundabouts are charac-

Table 3. Widths of modular elements - Italian standard

\begin{tabular}{|c|c|c|}
\hline Modular element & $\begin{array}{l}\text { Inscribed circle } \\
\text { diameter, m }\end{array}$ & Widths, m \\
\hline \multirow{3}{*}{$\begin{array}{l}\text { Lanes of the circulatory } \\
\text { roadway for one lane } \\
\text { entry legs }\end{array}$} & $\geq 40$ & 6.00 \\
\hline & from 25 to 40 & 7.00 \\
\hline & from 14 to 25 & $7.00-8.00$ \\
\hline \multirow{2}{*}{$\begin{array}{l}\text { Lanes of the circulatory } \\
\text { roadway for two lane } \\
\text { entry legs }\end{array}$} & $\geq 40$ & 9.00 \\
\hline & $<40$ & $8.50-9.00$ \\
\hline Entry legs $s^{\star *}$ & & $\begin{array}{l}3,50 \text { (one lane) } \\
6.00 \text { (two lane) }\end{array}$ \\
\hline \multirow{2}{*}{ Exit legs* } & $<25$ & 4.00 \\
\hline & $\geq 25$ & 4.50 \\
\hline
\end{tabular}

Notes: ${ }^{*}$ it must always be organized on a single lane, ${ }^{* *}$ organized at most with two lanes.

Table 4. Values of the geometric variables considered

\begin{tabular}{|l|l|}
\hline \multicolumn{1}{|c|}{ Geometric variables } & \multicolumn{1}{|c|}{ Values considered } \\
\hline$L_{\mathcal{c}}, \mathrm{m}$ & $2.75 ; 3.00 ; 3.25 ; 3.50 ; 3.75$ \\
\hline & $19 ; 20 ; 21 ; 22 ; 23 ; 24 ; 25 ; 26 ; 27 ; 28 ;$ \\
$\mathrm{ICD}=2 R_{\text {exit }}, \mathrm{m}$ & $29 ; 30 ; 31 ; 32 ; 33 ; 34 ; 35 ; 36 ; 37 ; 38 ;$ \\
& $39 ; 40 ; 41 ; 42 ; 43 ; 44 ; 45 ; 46 ; 47 ; 48 ;$ \\
& $49 ; 50$ \\
\hline$\theta,^{\circ}$ & $180 ; 170 ; 160 ; 150 ; 140 ; 130 ; 120$ \\
\hline \multirow{2}{*}{$R_{\text {app }} / R_{\text {entry }} / R_{\text {exit }} / R_{\text {dep }}}$, & $0 / 10 / 12 / 0 ; 50 / 10 / 12 / 48 ; 0 / 12 / 15 / 0 ;$ \\
$\mathrm{m}$ & $60 / 12 / 15 / 60 ; 0 / 15 / 18 / 0 ;$ \\
\hline
\end{tabular}

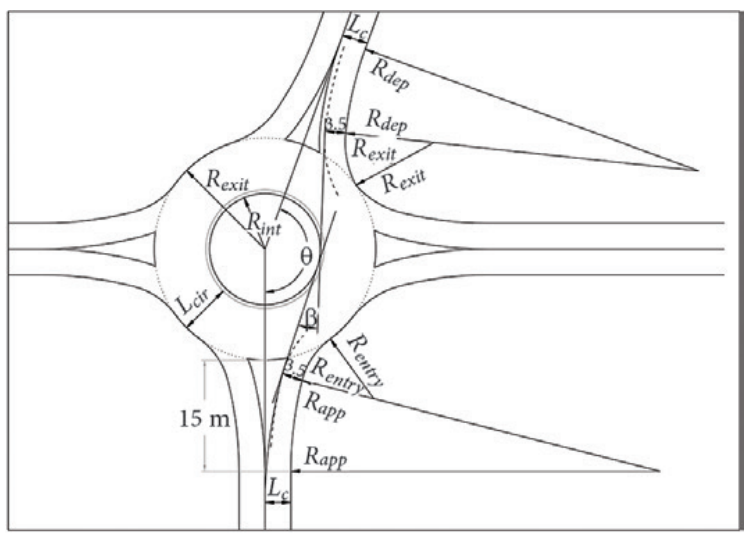

Figure 2. Geometric variables considered for the deviation angle calculation terized by non-mountable kerbs. Furthermore, the circulatory roadway must always be organized on a single lane.

The widths of the modular elements stated in the Standard are reported in Table 3.

\section{Research method}

For the aims of the research stated in the Introduction, more than 7.000 roundabouts were drawn in a CAD environment, and the deviation angle was reconstructed for each of them. The roundabouts drawn are not existing roundabouts, but rather hypothetically plausible ones, according to the Italian standards. The study considers only one-lane roundabout in rural areas, with divisional islands, and without pedestrian or bicycle crossings, sidewalks or traffic lights.

The high number of roundabouts drawn is due to the geometric parameters used as variables (Figure 2), which were selected by varying according to the ranges provided in the Italian standard (Table 3 ). A deviation angle $\geq 45^{\circ}$ indicates a good deflection of trajectories at roundabouts, for both the Italian and Swiss standards. For each combination of the geometric parameters, the smallest ICD value was obtained, for which the deviation angle check is satisfied.

The approach lane width $\left(L_{c}\right)$ is assumed equal to the departure lane width, taking into account all the possible widths laid down by the Italian standard. Roundabouts with an ICD of less than 19.00 m were excluded from the analysis because they are characterized by a fully mountable central island. In these cases, the lack of a nonmountable kerb around the central island makes the construction of the deviation angle impossible as indicated by the standard. Roundabouts with opposite legs inclined, up to 120 degrees, have been considered to take into account the cases where roads at intersections conflict with angles different than $90^{\circ}$.

Since the Italian standard potentially allows any dimension for the entry $\left(R_{\text {entry }}\right)$, approaching $\left(R_{a p p}\right)$, exit $\left(R_{\text {exit }}\right)$ and departing radii $\left(R_{\text {dep }}\right)$, the choice of $R_{\text {entry }}$ and $R_{\text {exit }}$ was made by taking into account the good design practices and guidance of central European countries presented before (Kennedy, 2007; Montella, Turner, Chiaradonna \& Aldridge, 2013). Regarding the approaching and departing radii, the Swiss standard (VSS, 1999), providing the $R_{a p p}$ to be 5 times the $R_{\text {entry }}$, and the $R_{\text {dep }}$ to be 4 times the $R_{\text {exit }}$, is used as reference. The case of the absence of the approaching and departing radius has also been considered to represent many real cases of roundabouts in Europe. The ranges of variation of the parameters, and the combinations of $R_{a p p}, R_{\text {entry }}, R_{\text {exit }}$ and $R_{\text {dep }}$ used are shown in Table. 4 .

The analysis of the considered hypothetical roundabouts was aimed at identifying the relationships between the deviation angle and the geometric parameters of roundabouts. Thereafter, a comparison between the deviation angle method and other two International methods is carried out, by using the same roundabouts plotted in CAD environment by using the Italian Standards (to allow a consistent comparison). 
The two methods on which the comparison is based are the entry path radius method and the German method. The first method was selected since it is the most widespread in the sample of countries considered in this article. In particular, the US graphical method was selected, rather than the British, Spanish or Swedish ones, since the "a", "b", and "c" coefficients shown in Figure if were deemed as more realistic for the trajectories of several types of vehicles. The second method selected for the comparison is the German method, which seems to be different from all the other ones.

As regards the entry path radius method, the fastest paths of the roundabouts previously tested were reconstructed by considering the indications of the US guidelines (Figure 1f and Sub-Section 1.2), and by varying the same geometric parameters as in the analysis before conducted (ICD, $\theta, L_{c}$ and $\left.R_{a p p} / R_{\text {entry }} / R_{\text {exit }} / R_{\text {dep }}\right)$. For each hypothetical roundabout, the fastest path was drawn and the related entry path radius was obtained. Hence, the entry speed was computed, by using Eq. (1) (related to positive super elevation).

As regards the German method, the check provides a positive outcome when the radius of the circulatory island is at least twice the approach lane width. Hence, to get the smallest ICD values, in order to satisfy the rule, the following equation was employed:

$$
4 L_{c}+2\left(L_{c i r}+0.5\right)
$$

where 0.5 is the width of the left shoulder (for all types of roundabouts) (m); and the value of $L_{c i r}$ is shown in Table 3 (in this case, it is always set to $7.00 \mathrm{~m}$ ) (m).

\section{Results}

The main results of the analysis are discussed in this section. The relationships between different geometric parameters of roundabouts and the deviation angle are reported first. Subsequently, the comparison between the deviation angle method, the entry path radius method (USA) and the German method is discussed.

\subsection{Identifying the relationships between geometric design parameters of roundabouts and the deviation angle}

The general results of the analysis are listed below:

1) the increase in ICD positively influences the deviation angle check (i.e. the angle increases);

2) reducing $\theta$ negatively influences the deviation angle check (i.e. the angle decreases);

3) reducing $L_{c}$ positively influences the deviation angle check;

4) the presence and the increase of the approaching $\left(R_{a p p}\right)$ and the departing radius $\left(R_{d e p}\right)$ negatively influence the deviation angle requirement;

5) differences in the circulatory roadway width $\left(L_{c i r}\right)$ between compact and large roundabouts and between compact and mini roundabouts (Table 3) negatively influence the deviation angle check;
6) the Italian $\beta$ recommendation ( $\beta$ no less than $45^{\circ}$ ) fails for any of the mini roundabouts or for many compact roundabouts (also for $\theta$ equal to $180^{\circ}$ );

7 ) the Italian $\beta$ recommendation ( $\beta$ no less than $45^{\circ}$ ) fails for $\theta$ below $140^{\circ}$.

The considerations listed above from point 1 to point 4 may be considered as universally valid, independently of the geographical area, whereas the results highlighted in points 5 to 7 are instead related to specific Italian geometric standards.

The first two findings about ICD and $\theta$ are predictable from immediate geometric considerations. As regards the approach and the departure lane width $\left(L_{c}\right)$, they depend on the roads approaching the roundabout. Therefore, it is difficult to act easily on these parameters to improve the deflection.

As concerns the approaching and the departing radius, in rural roundabouts, usually devoid of pedestrian or bicycle crossings, introducing both $R_{a p p}$ and $R_{\text {dep }}$ improve the intersection efficiency because it:

1) increases the roundabout capacity,

2) reduces the average occupation time,

3) ensures a proper separation among opposite traffic flows through the installation of larger splitter islands.

Guidance from reference standards (even International) indicating where the approaching radius has to begin is lacking and then, its beginning was set at $15 \mathrm{~m}$ from the circulatory roadway in this study. In this way, it is possible to optimize the connection between $R_{a p p}$ and $R_{\text {entry }}$ (or $R_{d e p}$ and $R_{e x i t}$ ), by allowing the insertion of sufficiently large splitter islands.

As regards the circulatory roadway $\left(L_{c i r}\right)$, the results show that its width greatly affects the deviation angle: the larger the width, the smaller the angle. As shown in Table 3, the Italian standard provides the increase in Lcir in correspondence with the decrease in ICD. A possible solution consists in assuming the $L_{c i r}$ constant (as provided in the Swiss standard) and made varying the truck apron. This solution is discussed later in this paper and generalized for other contexts.

As regards the $\theta$ angle, on one hand the deviation angle check is unmet for $\theta$ less than $140^{\circ}$, although it is accomplished for $\theta$ values close to $180^{\circ}$, by modifying the other geometric parameters. Hence, the deviation angle check can also be satisfied for legs crossing at roundabouts with $\theta$ less than $90^{\circ}$.

In addition to the qualitative discussion about these geometric relationships, the resulting deviation angles for different combinations of the geometric parameters: ICD, $\theta, L_{\mathcal{c}}, R_{\text {app }}, R_{\text {entry }}, R_{\text {exit }}, R_{\text {dep }}$ have been computed. A summary of the results obtained from the analyses conducted is shown in Table 5. The minimum ICD values, allowing $\beta$ values no more than $45^{\circ}$, are shown here, according to different geometric design parameters. 
Table 5. Minimum ICD values, which satisfy the $\beta$ recommendation ( $\beta$ up to $45^{\circ}$ ), according to different geometric parameters of the roundabouts

\begin{tabular}{|c|c|c|c|c|c|c|c|c|c|c|c|c|c|c|c|c|c|c|c|c|c|c|c|c|c|}
\hline \multirow{3}{*}{$\begin{array}{c}R_{\text {app }} / R_{\text {entry }} / \\
R_{\text {exit }} / R_{\text {dep }}, \mathrm{m}\end{array}$} & \multicolumn{25}{|c|}{$L_{c}$ in $\mathrm{m}$, when } \\
\hline & \multicolumn{5}{|c|}{$\theta$ equal to $180^{\circ}$} & \multicolumn{5}{|c|}{$\theta$ equal to $170^{\circ}$} & \multicolumn{5}{|c|}{$\theta$ equal to $160^{\circ}$} & \multicolumn{5}{|c|}{$\theta$ equal to $150^{\circ}$} & \multicolumn{5}{|c|}{$\theta$ equal to $140^{\circ}$} \\
\hline & 2.75 & 3.00 & 3.25 & 3.50 & 3.75 & 2.75 & 3.00 & 3.25 & 3.50 & 3.75 & 2.75 & 3.00 & 3.25 & 3.50 & 3.75 & 2.75 & 3.00 & 3.25 & 3.50 & 3.75 & 2.75 & 3.00 & 3.25 & 3.50 & 3.75 \\
\hline $0 /$ & 27 & 28 & 29 & 29 & 30 & 32 & 33 & 33 & 34 & 35 & 38 & 39 & 39 & 40 & $40^{*}$ & $40^{*}$ & $40^{*}$ & 41 & 42 & 42 & 48 & 48 & 49 & 50 & - \\
\hline $50 /$ & 30 & 3 & 1 & 3 & 33 & 34 & 35 & 3 & 1 & 37 & 40 & $40^{*}$ & $40^{*}$ & $40^{*}$ & $40^{*}$ & 12 & & & & 45 & 50 & - & - & - & - \\
\hline $0 /$ & 28 & 29 & 30 & 30 & 31 & 34 & 34 & 35 & 36 & 36 & 40 & $40^{*}$ & \begin{tabular}{|l|l|}
$40^{*}$ \\
\end{tabular} & $40^{*}$ & $40^{*}$ & 42 & 43 & 43 & 44 & 45 & - & - & - & - & - \\
\hline $60 / 12$ & 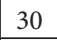 & 3 & 1 & 32 & 32 & 35 & 36 & 36 & 37 & 38 & $40^{*}$ & $40^{*}$ & $40^{*}$ & $40^{*}$ & $40^{*}$ & 43 & 11 & . & 4 & 46 & 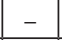 & - & - & - & - \\
\hline & 30 & 30 & 31 & 32 & 32 & 36 & 36 & 37 & 37 & 38 & $40^{*}$ & $40^{*}$ & $40^{*}$ & $40^{*}$ & $40^{*}$ & 45 & 46 & 46 & 47 & 48 & - & - & - & - & - \\
\hline $75 / 15 / 18 / 72$ & 30 & 31 & 32 & 32 & 33 & 36 & 37 & 37 & 38 & 39 & $40^{*}$ & $40^{*}$ & $40^{*}$ & $40^{*}$ & $40^{*}$ & 45 & 46 & 47 & 48 & 48 & - & - & - & - & - \\
\hline
\end{tabular}

Note: ${ }^{\star} L_{\text {cir }}$ equal to $6.00 \mathrm{~m}$ (large roundabouts).

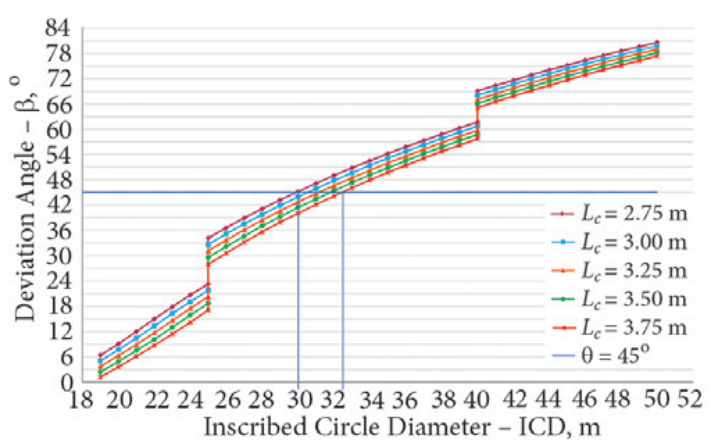

Figure 3. Deviation angle for roundabouts with $\theta$ equal to $180^{\circ}$ and $R_{\text {app }} / R_{\text {entry }} / R_{\text {exit }} / R_{\text {dep }}$ equal to $75 / 15 / 18 / 72, \mathrm{~m}$

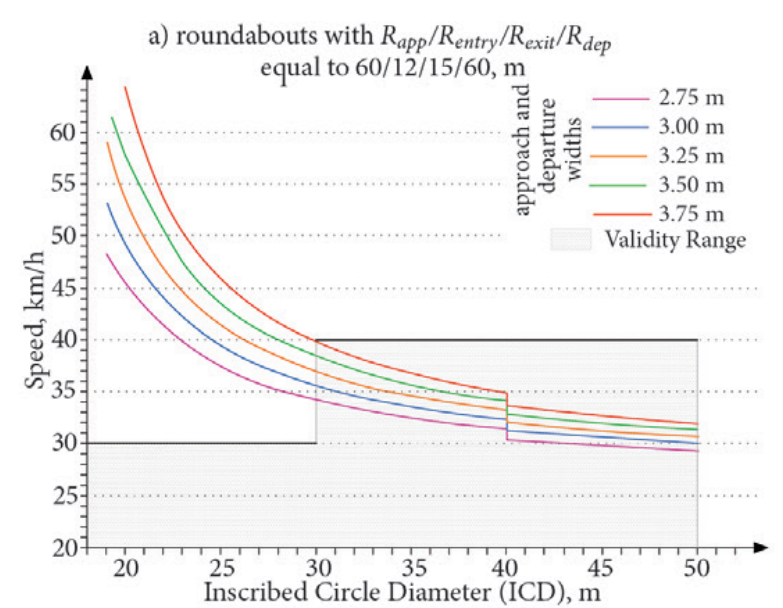

b) roundabouts with $R_{\text {app }} / R_{\text {entry }} / R_{\text {exit }} / R_{\text {dep }}$

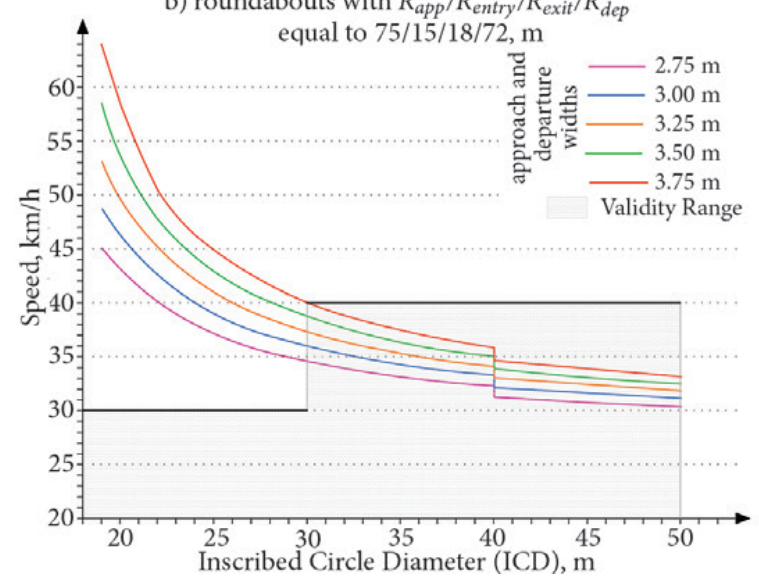

Figure 4. Checking the entry path radius method
Figure 3 (reported as an example of all the 42 diagrams plotted) shows the deviation angles for roundabouts with $\theta$ equal to $180^{\circ}$ and $R_{a p p} / R_{\text {entry }} / R_{\text {exit }} / R_{\text {dep }}$ equal to $75 / 15 / 18 / 72$, with ICD and $L_{c}$ varying. In this case, the $\beta$ recommendation is valid for roundabouts with an ICD more than $30.0 \mathrm{~m}$ or $32.5 \mathrm{~m}$ (compact roundabouts) depending on $L_{c}$.

It is important to note that roundabouts having ICD values equal to $25 \mathrm{~m}$ belong to either the mini or compact categories (which are drawn by using different values of $\left.L_{\text {cir }}\right)$. Hence, $10 \beta$ values are shown, instead of 5 . The same remark is valid for ICD equal to $40 \mathrm{~m}$, that is the boundary between large and compact roundabouts.

\subsection{Comparing the deviation angle method (Italy) with the entry path radius method (USA) and the German method}

The comparison between the deviation angle method and other two International methods is discussed in this section.

As regards the entry path radius method, the outcome of the checks is governed by the speed value $(\mathrm{V})$ of the entry path radius $R_{1}$, summarized in the following diagrams, where the range of validity of Table 2 is also shown.

Figure 4 reports the speeds correspondent with the entry path radius as a function of ICD; for different values of $L_{c}$ and for $R_{a p p} / R_{\text {entry }} / R_{\text {exit }} / R_{\text {dep }}$ equal to $60 / 12 / 15 / 60$ and $R_{\text {app }} / R_{\text {entry }} / R_{\text {exit }} / R_{\text {dep }}$ equal to $75 / 15 / 18 / 72$.

To note, the value of entry path radius (and the corresponding speed) appears to be independent of the $\theta$ angle. In fact, the deflection check in the US Guidelines is solely based on the entry radius measured on the fastest path, constrained by a fixed offset on the entrance line (Figure 1f). Hence, the rest of the fastest path is constrained by the $\theta$ angle, whereas the entry path radius cannot be influenced by it. However, the deviation angle method is strongly dependent on the $\theta$ angle, as discussed in section 3 (Table 4).

Table 5 reports the smallest ICD values to be used for fulfilling the entry path radius method (US standard), the German Method and the deviation angle method (Italian standard) respectively, by varying $L_{c}$ and $\theta$, for $R_{a p p} / R_{\text {entry }} / R_{\text {exit }} / R_{\text {dep }}$ equal to $60 / 12 / 15 / 60$ and $R_{\text {app }} / R_{\text {entry }} / R_{\text {exit }} / R_{\text {dep }}$ equal to $75 / 15 / 18 / 72$. Those results are derived from Figure 4, Table 4 and Eq. (4). 
Table 5. Minimum value of ICD able to satisfy the entry path radius and deflection angle methods

\begin{tabular}{|c|c|c|c|c|c|c|c|c|}
\hline \multirow{2}{*}{ Radius } & \multirow{2}{*}{$L_{c}, \mathrm{~m}$} & \multirow{2}{*}{$\begin{array}{c}\begin{array}{c}\mathrm{ICD}_{\text {min }}, \mathrm{m} \\
\mathrm{USA}\end{array} \\
\text { all values of } \theta\end{array}$} & \multirow{2}{*}{$\begin{array}{c}\begin{array}{c}\mathrm{ICD}_{\text {min }}, \mathrm{m} \\
\text { Germany }\end{array} \\
\text { all values of } \theta\end{array}$} & \multicolumn{5}{|c|}{$\begin{array}{l}\mathrm{ICD}_{\text {min }}, \mathrm{m} \\
\text { Italy }\end{array}$} \\
\hline & & & & $\begin{array}{l}\theta \text { equal } \\
\text { to } 180^{\circ}\end{array}$ & $\begin{array}{l}\theta \text { equal } \\
\text { to } 170^{\circ}\end{array}$ & $\begin{array}{l}\theta \text { equal } \\
\text { to } 160^{\circ}\end{array}$ & $\begin{array}{l}\theta \text { equal } \\
\text { to } 150^{\circ}\end{array}$ & $\begin{array}{l}\theta \text { equal } \\
\text { to } 140^{\circ}\end{array}$ \\
\hline \multirow{5}{*}{$\begin{array}{l}R_{\text {app }} / R_{\text {entry }} / R_{\text {exit }} / R_{\text {dep }} \\
\text { equal to } \\
60 / 12 / 15 / 60, \mathrm{~m}\end{array}$} & 2.75 & 30 & 26 & 30 & 35 & 40 & 43 & - \\
\hline & 3.00 & 30 & 27 & 30 & 36 & 40 & 44 & - \\
\hline & 3.25 & 30 & 28 & 31 & 36 & 40 & 45 & - \\
\hline & 3.50 & 30 & 29 & 32 & 37 & 40 & 45 & - \\
\hline & 3.75 & 30 & 30 & 32 & 38 & 40 & 46 & - \\
\hline \multirow{5}{*}{$\begin{array}{l}R_{a p p} / R_{\text {entry }} / R_{\text {exit }} / R_{d e p} \\
\text { equal to } \\
75 / 15 / 18 / 72, \mathrm{~m}\end{array}$} & 2.75 & 30 & 26 & 30 & 36 & 40 & 45 & - \\
\hline & 3.00 & 30 & 27 & 31 & 37 & 40 & 46 & - \\
\hline & 3.25 & 30 & 28 & 32 & 37 & 40 & 47 & - \\
\hline & 3.50 & 30 & 29 & 32 & 38 & 40 & 48 & - \\
\hline & 3.75 & 30 & 30 & 33 & 39 & 40 & 48 & - \\
\hline
\end{tabular}

As for the entry path radius method, the German method is also independent of the $\theta$ angle. Furthermore, both methods are independent of the radius $R_{a p p}, R_{\text {entry }}, R_{\text {exit }}$ and $R_{\text {dep }}$. Hence, this is deemed by the authors as a weakness of US standards (and the other standards based on the entry path radius) as well as in the German method, both independent of the angle $\theta$ and the radius of the entry and the exit legs. This finding becomes crucial in the case of conversion of existing junctions into roundabouts, when roads intersect with angles smaller than $90^{\circ}$ and the geometry of the roads cannot be varied due to boundary restrictions.

Furthermore, the minimum ICD value to satisfy the US standard is fixed, whereas the same check conducted through the German method varies according to the $L_{c}$ value. Comparing the results of the Italian method (even considering only $\theta$ equal to $180^{\circ}$ ) with the other methods, the Italian method proves to be the most conservative. In fact, in the same boundary conditions, higher diameters are necessary to satisfy the Italian deviation angle check. Moreover, it takes into account numerous geometric characteristics, ignored in the other two methods.

\section{Discussion}

The results presented in the previous section are discussed below. Starting from the results on the relationships between geometric parameters of the roundabouts and the deviation angle, the focus of the discussion is on both the comparison between the methods employed and the proposal of improvements for the Italian standard. Regarding the comparison between the three methods, they lead to similar results for roundabouts characterized by $\theta$ equal to $180^{\circ}$. However, reducing $\theta$ to $170^{\circ}$ highlights that both the entry path radius method and the German method are much less restrictive than the deviation angle method. In fact, the first two methods are unrelated to the $\theta$ angle. This is a general issue, especially for converting four-leg intersections without traffic lights into roundabouts when the roads intersect with angles smaller than $90^{\circ}$.
To note, by using the results of the analysis carried out, practitioners know in advance whether the requirement (or recommendation) about the deviation angle is satisfied, once the main design parameters are known. However, although the analysis has been conducted according to the construction provided by the Italian Standard, the results serve as a term of comparison independently of the specific local standards, in the case of similar roundabouts.

The analysis of the same results leads to remarks about the weaknesses of the Italian standard. Several roundabouts possibly realizable in Italy unmeet the $\beta$ recommendation. The recommendation is practically almost never satisfied for $\theta$ less than $140^{\circ}$. However, also for roundabouts with $\theta$ equal to $180^{\circ}$, the recommendation is always unmet for mini roundabouts and often unmet for compact roundabouts. On the contrary, the recommendation is always satisfied for large roundabouts and for $150^{\circ} \leq \theta \leq 180^{\circ}$. Values of $L_{\text {cir }}$ varying between large and compact roundabouts lead to non-compliance with the $\beta$ recommendation for several compact roundabouts. Whereas, although $L_{c i r}$ is kept equal to $6.00 \mathrm{~m}$ for compact roundabouts, the minimum ICD value reported in Table 5 shows a higher variability even for $\theta$ equal to $160^{\circ}$ (instead of being almost always equal to $40 \mathrm{~m}$ ).

Another interesting result to highlight is that, as well as the Italian standard, even the US and German verification give a negative deflection check for all mini roundabouts. In fact, the minimum ICD required to satisfy the deflection requirement based on the entry path radius method is $30 \mathrm{~m}$, whereas it is between $26 \mathrm{~m}$ and $30 \mathrm{~m}$ according to the German method.

Hence, research that is more specific is needed on the design of mini roundabouts with respect to deflection, independently of the method used and the particular country standards.

Moreover, since different remarks about the deflection requirement arose for different types of roundabouts, some proposals for improvements are provided below, differentiated for roundabout type, considering the rural context. Since 
this study used the geometric Italian standard as a reference, the following recommendations are essentially related to the Italian types of roundabouts (large, compact, mini). Potentially, they could be applied to other countries with similar geometric elements. However, further studies are needed to better address transferring these results to other countries.

\subsection{Large roundabouts $(\mathrm{ICD} \geq 40 \mathrm{~m})$}

The $\beta$ recommendation was fulfilled for all conventional roundabouts with $\theta$ angle included between $160^{\circ}$ and $180^{\circ}$. The $\beta$ recommendation is also satisfied for $\theta$ equal to $150^{\circ}$, especially for roundabouts characterized by small entry and exit radii or by both approaching and departing radii absent. Hence, further improvements are disregarded.

\subsection{Compact roundabouts $(25 \mathrm{~m} \leq \mathrm{ICD}<40 \mathrm{~m})$}

The $\beta$ recommendation was only fulfilled for some compact roundabouts. When either the angle $\theta$ is reduced, the approaching and the departing radii are inserted, or the entry and the exit radii are increased, the situation gets worse.

The differences in the circulatory roadway widths in the Italian standard, between compact and mini roundabouts ( $7 \mathrm{~m}$ and $8 \mathrm{~m}$, respectively) and between compact and conventional roundabouts ( $7 \mathrm{~m}$ and $6 \mathrm{~m}$, respectively) negatively affect the $\beta$ check. Assuming a constant width of the circulatory roadway equal to $6 \mathrm{~m}$ may be an improvement, even for compact and mini roundabouts, in

a) deviation angle for roundabouts with $\theta$ equal to $180^{\circ}$ and $R_{\text {app }} / R_{\text {entry }} / R_{\text {exit }} / R_{\text {dep }}$ equal to $75 / 15 / 18 / 72, \mathrm{~m}$ and $L_{\text {cir }}$ equal to $6 \mathrm{~m}$

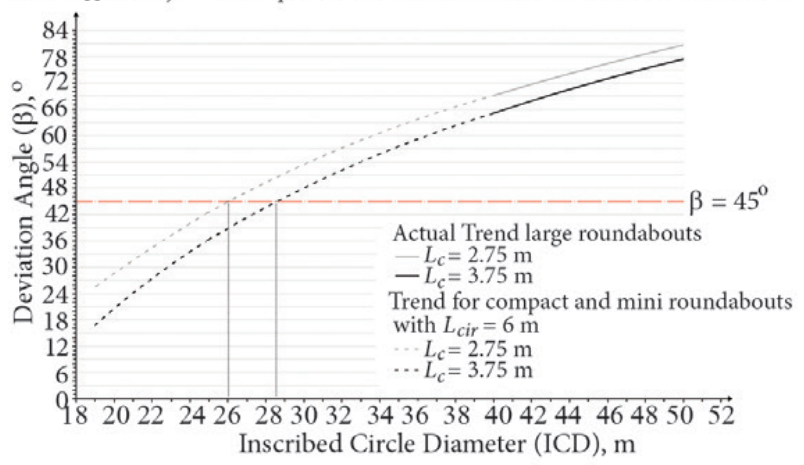

b) examples of truck apron highly unattractive for cars

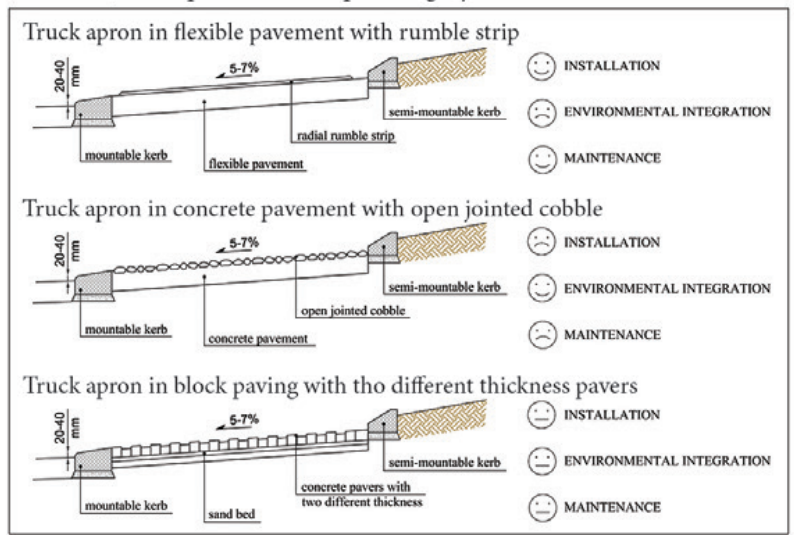

Figure 5. Extending the fulfilment of the $\beta$ check to a larger number of compact roundabouts order to cut the discontinuities at ICD equal to $40 \mathrm{~m}$ and $25 \mathrm{~m}$. The same diagram as in Figure 3 has been plotted in Figure $5 \mathrm{a}$, considering a single width (with $\theta$ equal to $180^{\circ}$ and the unfavourable case of $R_{a p p} / R_{\text {entry }} / R_{\text {exit }} / R_{\text {dep }}$ equal to 75/15/18/72, m).

The proposed solution about the unique circulatory roadway width is eventually completed by inserting a truck apron in compact roundabouts too, to allow easy manoeuvring of heavy vehicles. The Italian standard recommends drawing the $\beta$ angle by plotting the tangent lines to the non-mountable kerb of the central island. In fact, the truck apron is realized with a fully mountable kerb and with comfortably carriage able materials. A proposal for an improved solution consists in realizing the truck apron with a material easily mountable by heavy vehicles, but at the same time highly unattractive for cars. Several materials and solutions are potentially usable for giving discomfort to the car drivers in terms of noise and rolling due to surface irregularities. Some examples are proposed in Figure 5b. Similar solutions are already provided in Dutch and in UK guidelines. The width of the truck apron will depend on the dimensions of the heavy vehicles (resulting in the swept path), related to the inscribed circle diameter. Opting for a flat surface will be possible (to cut noise), with the same super elevation of the circulatory roadway (to cut the chance of overturning), but with a mountable kerb of $5 \mathrm{~cm}$ to $7 \mathrm{~cm}$ high.

Using truck aprons highly unattractive for cars, the deviation angle is proposed to be drawn by plotting the tangent to the outer part of the truck apron instead of the innermost, ensuring the $\beta$ checks for almost all compact roundabouts. The case shown (check satisfied for ICD equal to $26.25 \mathrm{~m}$ with $L_{c}$ equal to $2.75 \mathrm{~m}$ and for ICD equal to $28.5 \mathrm{~m}$ with $L_{c}$ equal to $3.75 \mathrm{~m}$ ) is the worst case for the used radii dimensions. The recommendation is satisfied with ICD equal to $25 \mathrm{~m}$, being both the lower entry and exit radii present.

Moreover, a slightly lower limit of the angle $\beta$ is proposed, in order to allow greater design versatility for compact roundabouts, by reducing it from 45 to 40 degrees, as required by some local Swiss Guidelines. In fact, some studies have shown accident increasing for deviation angles less than 40 (Huber \& Bühlmann, 1994).

\subsection{Mini roundabouts $(14 \leq \mathrm{ICD}<25 \mathrm{~m})$}

Mini roundabouts need specific regulations to cut the approaching and circulating speeds. For mini roundabouts, the $\beta$ angle is potentially usable as an indicator of traffic calming measures to be implemented. In particular, for deviation angles between 30 and 40 degrees, the implementation of light traffic calming devices (enhanced horizontal and vertical road signs, rumble strips, optical devices) are proposed. For $\beta$ angles less than $30^{\circ}$, (considered possible by Huber \& Bühlmann, 1994), implementing more significant traffic calming devices is adviced (raised platforms, chicanes, automatic speed checks). 
Several International studies, Guidelines and Standards include implement traffic calming devices in mini roundabouts (Antov, Abel, Sürje, Rõuk, \& Rõivas, 2009; Rossi, Gastaldi, Biondi, \& Mulatti, 2013; WSDOT, 2017). However, further studies have to be carried out to relate each traffic-calming device to the context and to the main function of the roundabout under examination. Finally, to make this proposal applicable, traffic-calming devices have to be standardized in countries where standards and regulations about their design are lacking.

Moreover, the assessment of geometric elements of mini roundabouts (and particularly the truck apron) has to be based on the worst design vehicles (in terms of dimensions) supposed in the roundabout traffic flow. This recommendation is proposed as an improvement for standards of countries where it is absent, such as in Italy.

\section{Conclusions}

This study was focused on the deviation angle method (used by Italian and Swiss standards), but a comparison with the entry path radius method (used in several countries) and with the German method has been carried out to check their compatibility or differences. The study was limited to single-lane four-legged roundabouts in rural areas. Moreover, the Italian standard was used to build more than 7.000 hypothetical roundabouts in a Computer-Aided Design environment, to check their deviation angle and compare the results with both the US entry path radius method and with the German method.

The following general conclusions from this study are drawn:

1. This study helps practitioners to know in advance the deflection angle value before the design process, once the boundary conditions are known.

2. The entry path radius and the German methods are much less restrictive than the deviation angle method for roundabouts with non-orthogonal intersecting roads or with different entry and exit legs radii, since the deviation angle is strongly dependent on the mutual inclination of the roads and on these radii.

3. The three methods considered led to a negative check for all mini roundabouts (inscribed circle diameter is equal from $14-25 \mathrm{~m}$ ).

The study has also led to the following conclusions specifically devoted to improve Italian regulations:

1. The use of a constant width of the circulatory roadway assumed to be equal to $6 \mathrm{~m}$ in this study, with a truck apron highly unattractive for cars, extend the Italian deviation angle recommendation ( $\beta$ more than $45^{\circ}$ ) to be valid for almost all roundabouts with an inscribed circle diameter greater than $25 \mathrm{~m}$.

2. Mini roundabouts need specific regulation in standards of countries (e.g. Italy) where they are considered in a similar fashion and with similar arrangements for larger roundabouts.

To some extent, some of the findings are transferrable to other countries, whereas some others are specifically related to the standards used, as explained in the paper. Hence, further investigations are needed for roundabouts in urban areas and for multi-lane roundabouts in rural areas. Nevertheless, a more general framework is a challenge for future studies, in order to spread the results of comparison between different deflection methods in other countries, through general tools.

\section{References}

Afezolli, A., \& Paçi., E. (2012). Roundabouts control, using the maximum entry path radii speed. Journal of Institute AlbShkenca, 2, 277-283. ISSN 2073-2244.

Ambros, J., Novák, J., Borsos, A., Hóz, E., Kieć, M., Machciník, Š., \& Ondrejka, R. (2016). Central European comparative study of traffic safety on roundabouts. Transportation Research Procedia, 14, 4200-4208. https://doi.org/10.1016/j.trpro.2016.05.391

Antov, D., Abel, K., Sürje, P., Rouk, H., \& Roivas, T. (2009). Speed reduction effects of urban roundabouts. Baltic Journal of Road \& Bridge Engineering, 4(1), 22-26.

https://doi.org/10.3846/1822-427X.2009.4.22-26

Arndt, O. (2008). Speed control at roundabouts: use of maximum entry path radii. ARRB Conference, $23^{\text {rd }}$. Adelaide, South Australia, Australia.

Aumann, P. (2015). Guide to road design part 4B: roundabouts (No. AGRD04B-15). Austroads. Australia.

Bezina, Š., Stančerić, I., \& Ahac, S. (2017). Design vehicles and roundabout safety - review of Croatian design guidelines. Transport Infrastructure and Systems: Proceedings of the AIIT International Congress on Transport Infrastructure and Systems (p. 237). Rome, Italy. CRC Press.

https://doi.org/10.1201/9781315281896-33

Colonna, P., Berloco, N., Intini, P., Perruccio, A., \& Ranieri, V. (2016). Evaluating skidding risk of a road layout for all types of vehicles. Transportation Research Record: Journal of the Transportation Research Board, (2591), 94-102. https://doi.org/10.3141/2591-11

CROW (1998). Eenheid in Rotondes [Standards for Roundabouts], publicatie 126 .

Easa, S., \& Mehmood, A. (2004). Optimizing geometric design of single-lane roundabouts: consistency analysis. Canadian Journal of Civil Engineering, 31(6), 1024-1038.

https://doi.org/10.1139/104-066

Forschungsgesellschaft fur Strassen und Verkherswesen [Research Institute for Road and Transport] (FGSV). (2006). Merkblatt fur die Anlage von Kreisverkehren [Guide for the Installation of Roundabouts].

Flannery, A. (2001). Geometric design and safety aspects of roundabouts. Transportation Research Record: Journal of the Transportation Research Board, (1751), 76-81. https://doi.org/10.3141/1751-09

Huber, C., \& Bühlmann, F. (1994). Sicherheit von Kreiselanlagen, Erfahrungen und vorl vorle Empfehlungen [Safety at roundabouts, experiences and preliminary recommendations]. Swiss Bureau for Accident Prevention (BFU), Berne, Switzerland.

Kennedy, J. (2007). International comparison of roundabout design guidelines. TRL.

Mehmood, A., \& Easa, S. M. (2006). Optimizing geometric design of roundabouts: multi-objective analysis. Canadian Journal of Civil Engineering, 33(1), 29-40. https://doi.org/10.1139/105-078

Ministerio de Fomento [Ministry of Public Works and Transport]. (1999). Recomendaciones sobre glorietas [Guidelines for Roundabouts]. 
Ministero delle Infrastrutture e dei Trasporti [Ministry of Public Works and Transport]. (2006). Decreto Ministeriale: Norme funzionali e geometriche per la costruzione delle intersezioni stradali [Operational and geometric standards for the construction of road intersections]. Gazzetta Ufficiale (170).

Montella, A. (2011). Identifying crash contributory factors at urban roundabouts and using association rules to explore their relationships to different crash types. Accident Analysis \& Prevention, 43(4), 1451-1463. https://doi.org/10.1016/j.aap.2011.02.023

Montella, A., Turner, S., Chiaradonna, S., \& Aldridge, D. (2013). International overview of roundabout design practices and insights for improvement of the Italian standard. Canadian Journal of Civil Engineering, 40(12), 1215-1226. https://doi.org/10.1139/cjce-2013-0123

National Cooperative Highway Research Program (NCHRP). (2000, 2010). Roundabouts: an Informational Guide. Washington DC.

Pilko, H. (2017). Roundabout design guidelines: case study of Croatia. Transport Infrastructure and Systems: Proceedings of the AIIT International Congress on Transport Infrastructure and Systems (p. 9). Rome, Italy. CRC Press. https://doi.org/10.1201/9781315281896-3

Rodegerdts, L., et al. (2010). Roundabouts: an informational guide (National Cooperative Highway Research Program, Report 672, Second Edition). Transportation Research Board.

Rossi, R., Gastaldi, M., Biondi, F., \& Mulatti, C. (2013). Warning sound to affect perceived speed in approaching roundabouts: experiments with a driving simulator. Procedia-Social and Behavioral Sciences, 87, 269-278.

https://doi.org/10.1016/j.sbspro.2013.10.609
Sacchi, E., Bassani, M., \& Persaud, B. (2011). Comparison of safety performance models for urban roundabouts in Italy and other countries. Transportation Research Record: Journal of the Transportation Research Board, (2265), 253-259. https://doi.org/10.3141/2265-28

Sadeq, H., \& Sayed, T. (2016). Automated roundabout safety analysis: diagnosis and remedy of safety problems. Journal of Transportation Engineering, 142(12), 04016062. https://doi.org/10.1061/(asce)te.1943-5436.0000887

Service détudes Techniques des Routes et Autoroutes [Service of technical studies on highways and freeways] (SETRA). (1998). The design of interurban intersections on major roads: at-grade intersections. Centre de la Sécurité et des Techniques Routières.

Spacek, P. (2004). Basis of the Swiss design standard for roundabouts. Transportation Research Record: Journal of the Transportation Research Board, (1881), 27-35. https://doi.org/10.3141/1881-04

Schweizerischer Verband der Strassen- und Verkehrsfachleute [Swiss Association of Road and Transportation Experts] (VSS). (1999). Carrefours, Carrefours Giratoires [Intersections. Roundabouts]. SN 640 263. Zurich, Switzerland.

Tollazzi, T. (2015). Alternative Types of Roundabouts. An Informational Guide. Springer. https://doi.org/10.1007/978-3-319-09084-9

Trafikverket [Swedish Transport Administration]. (2015). Publikation 2015:087. VGU (Vägar och gators utformning) [Guidelines for the design of roads and streets].

UK Highways Agency. (2007). Design manual for roads and bridges. TD 16/07: Geometric design of roundabouts.

Washington State Department of Transportation (WSDOT). (2017). Roundabouts, Chapter 1320. In Design Manual M 22-01.14. 